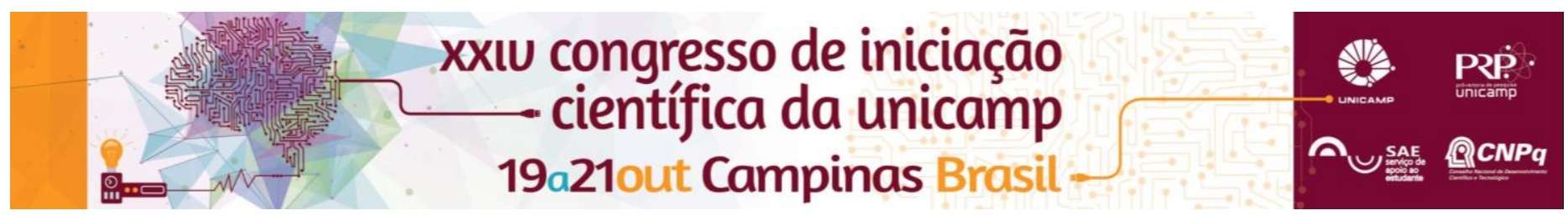

\title{
AVALIAÇÃO DA PRECIPITAÇÃO ATMOSFÉRICA EM REGIOES METROPOLITANAS
}

\author{
Jessica Silva Goulart*, Ciro Ferreira Lopes, Adna Azevedo Silva, Edson Aparecido Abdul Nour, Aparecida Silva \\ Santos Carbone, Angela dos Santos Barreto,Fernando Pena Candello, Diogenes Cortijo Costa
}

\section{Resumo}

A precipitação atmosférica é considerada um importante processo de remoção de poluentes da atmosfera. A caracterização química desta matriz ambiental pode indicar a presença de espécies inorgânicas proveniente de fontes naturais e antrópicas de uma determinada região.A avaliação da água de chuva apresentou acidez em todos os eventos de chuva amostrados em regiões industriais.

Palavras-chave: dispersão de poluentes, poluição atmosferica, chuva acida

\section{Introdução}

O crescente desenvolvimento de indústrias e áreas urbanas contribui para o aumento da poluição atmosférica devido às emissões antrópicas. A água de chuva é um importante processo de remoção de poluentes da atmosfera, e ao analisá-la determina-se a presença de espécies inorgânicas advindas de fontes naturais e antrópicas de uma região. Em decorrência do rápido desenvolvimento das indústrias e centros urbanos ocorre um aumento significativo na poluição atmosférica relacionado a grande emissão proveniente de veículos e processos industriais. Dentre os principais poluentes podem-se citar compostos de enxofre, carbono e nitrogênio, geralmente agregados ao material particulado atmosférico na forma de aerossóis ou de precipitação úmida e seca. Um importante processo de remoção de espécies inorgânicas e orgânicas da atmosfera é a precipitação atmosférica, úmida ou seca. E ao analisá-la, pode-se determinar a presença de espécies inorgânicas, proveniente de fontes naturais e antrópicas em uma determinada região. $\mathrm{O}$ processo de formação dos poluentes atmosféricos pode ocorrer de duas formas: primários quando os poluentes são emitidos à atmosfera diretamente pelas fontes emissoras; e secundários, quando formados através de reações dos poluentes primários na atmosfera. O principal objetivo deste projeto foi determinar $\mathrm{O}$ principal objetivo deste projeto foi determinar o $\mathrm{pH}$, a condutividade, turbidez na água de chuva coletada pelos discentes participantes do programa.

\section{Resultados e Discussão}

No período da presente bolsa, foram realizadas várias atividades, com o intuito de aprimorar o conhecimento da temática a ser estudada. As amostras foram coletadas nas residências dos discentes durante o período chuvoso para posterior análise nas dependências do LABSAN. A figura 1 apresenta os discentes preparando as respectivas amostras.

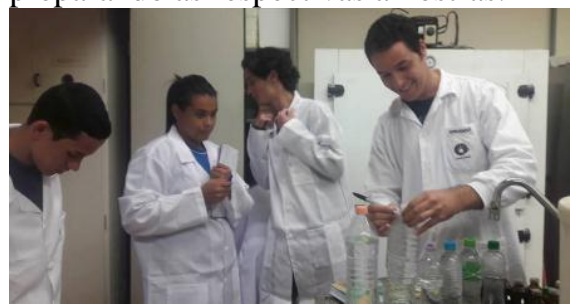

Figura1: Preparação das amostras

A metodologia compreendeu análises laboratoriais para parâmetros químicos, como $\mathrm{pH}$, condutividade, turbidez, nitrato e sulfato. Os resultados analíticos estão apresentados a seguir na tabela 1:

Tabela 1: Resultados

\begin{tabular}{|c|c|c|c|c|c|c|}
\hline Amostra & Data & $\mathrm{pH}$ & $\begin{array}{c}\text { Turbidez } \\
\text { UT }\end{array}$ & $\begin{array}{c}\text { Condutividade } \\
\mu S / \mathrm{cm}\end{array}$ & $\begin{array}{l}\text { Nitrato } \\
\text { mg/L }\end{array}$ & SOX mg/L \\
\hline \multirow[t]{2}{*}{ 1-Marcella } & $25 / \mathrm{mai} \mathrm{A}$ & 7,41 & $\begin{array}{r}2,8 \\
\end{array}$ & 53,9 & 0,7 & 1,16 \\
\hline & 02/jun $\mathrm{B}$ & 6,6 & 2,61 & 9,2 & & \\
\hline \multirow[t]{3}{*}{ 2-Cida } & \begin{tabular}{l|l}
$25 /$ mai & $A$ \\
\end{tabular} & 7,01 & 1,2 & 12 & 0,7 & 0,7 \\
\hline & 01/jun $\mathrm{B}$ & 5,27 & 2,26 & 9,52 & & \\
\hline & 02/jun $\mathrm{C}$ & 7,6 & 0,67 & 6,72 & & \\
\hline \multirow[t]{2}{*}{ 3-Roberto } & 01/jun $\mathrm{A}$ & 7,1 & 1,4 & 22,1 & 0,4 & 1,02 \\
\hline & $05 / j$ un $B$ & 7,29 & 2,9 & 47,6 & & \\
\hline \multirow[t]{2}{*}{ 4-Jessica } & 25/mai A & 7,49 & 1,3 & 14,3 & 0,6 & 0,98 \\
\hline & 05/jun $\mathrm{B}$ & 6,35 & 14,4 & 1,16 & & \\
\hline \multirow[t]{3}{*}{ 5-Lucas } & 25/mai A & 7,44 & 2,6 & 28 & 0,4 & 1,01 \\
\hline & 30/mai B & 6,71 & 0,73 & 33,7 & & \\
\hline & 03/jun $\mathrm{C}$ & 6,74 & 1,37 & 39,7 & & \\
\hline 6-Isabelle & 25/mai A & 6,9 & 2,5 & 21,2 & 0,6 & 0,93 \\
\hline- & 30/mai B & 5,98 & 1,65 & 21,5 & & \\
\hline- & 01/jun $\mathrm{C}$ & 6,52 & 0,59 & 9,7 & & \\
\hline- & 02/jun $\mid \mathrm{D}$ & 5,9 & 1,4 & 20 & & \\
\hline \multirow[t]{3}{*}{ 7-Ciro } & 25/mai A & 6,49 & 10,1 & 0,8 & & \\
\hline & 29/mai B & 5,62 & 9 & 2,1 & & \\
\hline & 01/jun $\mathrm{C}$ & 4,84 & 13,6 & 0,6 & & \\
\hline 8-Angela & 05/jun $\mid \mathrm{A}$ & 6,38 & 8,6 & 1,9 & & \\
\hline
\end{tabular}

Do ponto de vista da análise química, a chuva ácida corresponde àquela em que o pH se apresenta inferior a 5,65 (Baird, 2002).O pH é um parâmetro necessário para a avaliação da ocorrência de chuva ácida, uma vez que seu valor está diretamente relacionado com o teor de íons de hidrogênio livre, expressando o grau de acidez ou alcalinidade. Logo as amostras que apresentaram $\mathrm{pH}$ ácido foram as $2 \mathrm{~B}$ coletadas na cidade de Paulínia, e as amostras 7B e 7C coletadas em. Campinas no bairro Vila Boa Vista ambos em áreas industriais.

\section{Conclusões}

A avaliação da água de chuva apresentou acidez em todos os eventos de chuva amostrados em regiões industriais, As massas de ar influenciam os ventos, que ao desaparecerem com o obstáculo que o cerca, favorece uma formação de nuvens, estando na atmosfera poluído, tudo que há nele, irá voltar à Terra na condição de chuvas ácidas.

\section{Agradecimentos}

E sim criamos laços!!!

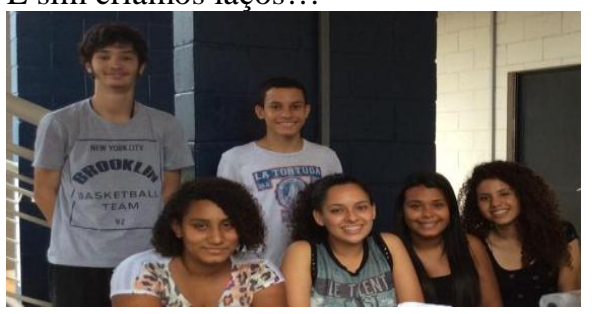

XXIV Congresso de Iniciação Científica da UNICAMP 